\title{
Malnutrition - Diarrhea Cycle: How to break this?
}

\author{
Patel $\mathbf{U}^{1}$, Gedam DS ${ }^{2}$ \\ ${ }^{1}$ Dr Umesh Patel, ${ }^{2}$ Dr D Sharad Gedam, Both are member of Editorial board \& affiliated with L N Medical College, Bhopal, \\ MP, India
}

Corresponding author: Dr Umesh Patel, Email: drumeshpatel@gmail.com

\begin{abstract}
In most of developing world Infectious diseases like acute gastroenteritis \& Pneumonia are leading causes of Infant \& Under five mortality. Malnutrition when present further increases morbidity \& mortality of both diseases.
\end{abstract}

Diarrhea is one of the most prevalent serious health problems of young children. According to the latest estimates of child mortality issued by UNICEF, pneumonia and diarrhea continue to be the leading killers of children under the age of five worldwide. Pneumonia and diarrhea, respectively, are responsible for $17 \%$ and $9 \%$ of global child deaths [1]. It is the second leading cause of death in children under 5 years of age. Globally around 1.7 billion cases of diarrhea and around 760,000 children death occur each year due to diarrhea and associated complications. The relationship between malnutrition and diarrhoea is bidirectional. Diarrhea is also leading cause of malnutrition in children under 5 years of age. Epidemiological studies have demonstrated a marked negative relationship between diarrhoea and physical growth and development of a child. Each day of illness due to diarrhoea produces a weight deficit of 2040 gms. Malnutrition often results in death or long-term physical and developmental delays in young children. Being malnourished makes a child more susceptible to diarrhea, causing more frequent and more severe diarrheal episodes. Malnutrition predisposes children to a greater incidence and duration of diarrhea, and malnutrition can be triggered or worsened by significant diarrhoea [2]. Publication of the WHO monograph, "Interactions of Nutrition and Infection," in 1968 by Scrimshaw, Taylor and Gordon stimulated many scientists to pursue further research on these issues [3]. Last 10 years status shows that the incidence of diarrhea is virtually unchanged but estimated global mortality is decreased [4]. Despite decreased in mortality, diarrheal disease is a still significant problem for whole world.

Diarrhea and malnutrition, alone or together, constitute major causes of morbidity and mortality among children throughout the tropical world. Children who are malnourished or have impaired immunity, are most at risk of life-threatening diarrhoea. In poor communities, like India, the relationship between malnutrition and diarrhea frequently leads to a vicious cycle. This cycle causes stunting and cognitive impairment. Diarrhea and linear growth faltering continue to burden low-income countries and are among the most important contributors to poor health during early childhood [5].

Poor micronutrient status is a risk factor for severe diarrheal illness [6]. Although recently after ORS and zinc has received most attention, but vitamin A, folic acid and cobalamine also have been implicated $[7,8,9]$. Worldwide, 780 million individuals lack access to improved drinking-water and 2.5 billion lack improved sanitation. In developing countries, less than 3 years old children, suffers on average 3 episode of diarrhea every year. Diarrhea mostly results from contaminated food and water sources.

Over the past few decades, global, regional, national, and local efforts to improve child health have been immensely successful in slashing child mortality worldwide; rates of child mortality have consistently decreased each year since the 1990s. Fortunately, the health community today possesses the tools needed to stop this cycle and aggressively tackle both diarrhea and malnutrition in low-income countries. The available solutions including good infant feeding practices such as exclusive breastfeeding upto 6 months, appropriate supplementary food during critical time from 6 months to 2 years of life, appropriate maternal nutrition during pregnancy and lactation, and increased micronutrients such as Vitamin A, and zinc therapy-are both costeffective and proven to improve nutritional status and reduce diarrheal disease in children. Decades of research have produced an extensive evidence base to support the benefits of breastfeeding for child health and nutrition. Exclusive breastfeeding for the first six months of a child's life is a widely accepted best practice that is a highly effective strategy for preventing and reducing pneumonia and diarrhea mortality and morbidity [11]. 
In 2013, the Global Action Plan for the Prevention and Control of Pneumonia and Diarrhea (GAPPD) was developed and issued by the World Health Organization (WHO) and UNICEF, outlining key interventions that should be universally adopted, with the goal of ending preventable pneumonia and diarrhea mortality in children by 2025 [10]. GAPPD emphasizes the need for an integrated approach to ending preventable deaths due to pneumonia and diarrhea and promotes the use of interventions that are known to be effective. These include interventions that protect child health, prevent children from falling ill to pneumonia and diarrhea, and treat affected children appropriately [10].

WHO also working with different countries to decrease the diarrheal episodes in children by Promoting national policies and investments that support case management of diarrhoea and its, Conducting research to develop and test new diarrhoea prevention and control strategies in this area, Building capacity in implementing preventive interventions, including sanitation, source water improvements, and household water treatment and safe storage, Developing new health interventions, such as the rotavirus immunization and Helping to train health workers, especially at community level.

Thus, pneumonia and diarrhea should be top national priorities that are addressed with urgency and policy makers should also change their views by giving adequate attention above the health equity or economic perspective.

Gupta et al in his research paper in this issue discussed about relationship between Malnutrition and diarrhea. Wasting is associated with diarrhea more frequently [12].

\section{References}

1. UNICEF. (2013). Committing to Child Survival: A Promise Renewed. Progress Report 2013.

Retrieved from http://www.unicef.org/publications/files/APR Progress_Report_2013_9_Sept_2013.pdf

2. Lima AA, Fang G, Schorling JB, De Albuquerque L, Mcauliffe JF, Mota S, Leite R, Guerrant RL. Persistent diarrhea in Northeast Brazil: etiologies and interactions with malnutrition. Acta Paediatrica, 1992, 81(Suppl. 381):39-44.

3. Scrimshaw NS, Taylor CE, Gordon AJE. Interactions of Nutrition and Infection. 1968. WHO monograph series no. 57 World Health Organization Geneva, Switzerland. 4. Bern C, Martines J, de Zoysa I, Glass RI. The magnitude of the global problem of diarrheal disease: a tenyear update. Bull WHO 1992;70:705-14.

5. Richard SA, Black RE, Gilman RH, Guerrant RL, Kang G, Lanata CF, Mølbak K, Rasmussen ZA, Sack RB, Valentiner-Branth P, Checkley W; Childhood Malnutrition and Infection Network. Catch-up growth occurs after diarrhea in early childhood. J Nutr. 2014 Jun;144(6):965-71.

6. Fischer Walker CL, Black RE. Micronutrients and diarrheal disease. Clin Infect Dis. 2007;45 Suppl 1:S737.

7. Brown KH, Peerson JM, Baker SK, Hess SY. Preventive zinc supplementation among infants, preschoolers, and older prepubertal children. Food Nutr Bull. 2009;30:S12-40.

8. Grotto I, Mimouni M, Gdalevich M, Mimouni D. Vitamin A supplementation and childhood morbidity from diarrhea and respiratory infections: a meta-analysis. J Pediatr. 2003;142:297-304.

9. Manger MS, Taneja S, Strand TA, Ueland PM, Refsum H, Schneede J, Nygård O, Sommerfelt H, Bhandari N. Poor Folate Status Predicts Persistent Diarrhea in 6- to 30-Month-Old North Indian Children. J. Nutr. 2011 Dec; 141(12): 2226-32.

10. WHO/UNICEF. (2013). Ending Preventable Child Deaths from Pneumonia and Diarrhoea by 2025. The Integrated Global Action Plan for Pneumonia and Diarrhea (GAPPD). Geneva. Retrieved from http://www.unicef.org/media/files/Final_GAPPD_main_ Report-_EN-8_April_2013.pdf

11. Lamberti LM, Fischer Walker CL, Noiman A, Victora C, Black RE. Breastfeeding and the risk for diarrhea morbidity and mortality. BMC Public Health.2011; 11(Suppl 3): S15

12. Gupta A. Prevalence of Diarrhoea and its association with Wasting, Age, and Gender in Children below Five years of age. Int J Med Res Rev 2014;2(4):291- 295.

\section{How to cite this article?}

Patel U, Gedam DS. Malnutrition - Diarrhea Cycle: How to break this? Int J Med Res Rev 2014;2(4):277- 278. doi:10.17511/ijmrr.2014.i04.01 